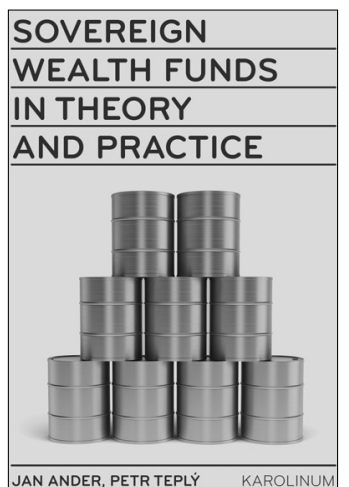

JAN ANDER, PETR TEPLY YY KAROLINUM

\title{
SOVEREIGN WEALTH FUNDS IN THEORY AND PRACTICE
}

\author{
Authors: Jan Ander, Petr Teplý \\ Publisher: Karolinum Press, 2014
}

This thesis was based on the scientific research of the authors PhDr. Petr Teplý, Ph.D. and Ing. Jan Ander. The aim is to provide readers acquainted with sovereign funds (Sovereign Wealth Funds, "SWF"), including their macroeconomic and microeconomic perspective. The thesis also deals with the foundation, development and current and future issues related to SWF. SWF have become an important part of the global financial system in recent years. SWF are state-owned funds that are set up for different purposes (at the end of 2013, SWF managed over 6 trillion USD). SWFs are not a new phenomenon and some of them have been existing for tens of years (e.g. in Kuwait, Abu Dhabí, Singapur). The monograph is intended mainly for university students, however, due to its focus it will also find its readers among those who want to learn more about the issue.

The publication is divided into three main parts. In the first part, the authors analyze the theoretical bases - including the current state of scientific knowledge about the subject, which is essential for understanding the empirical analysis in the second part of the work. The basic concepts, SWF investment strategies, key trends and transactions are explained. This issue is not much covered in the foreign or Czech literature. The second part focuses on the SWF in terms of empirical analysis, including the assessment of their impact on the global economy. The authors deal with the SWF transparency (using two indices - Linaburg-Maduell Index of Transparency and The Peterson Institute's Index of Transparency). The issues of the theoretical foundation of SWF and their influence on economy in the Czech Republic are also described. The final section presents the main conclusions and recommendations arising from the previous parts of the publication. One of the partial conclusions of the authors is that the establishment and operation of the SWF in the Czech Republic would have a positive impact on the public finances, but only if the required conditions are met. But they also recognize that the emergence of SWF in the Czech Republic has gone largely unnoticed. There is no offer made by politicians to set up a SWF, nor any demand from the side of their voters.

From the pedagogical point of view, it is appropriate to highlight the particular integrity and logical arrangement of the work. The monograph contains a large number of figures and tables, which perfectly complement the theoretical and empirical analysis on the issue of SWF. Some images and tables would be more appropriate, if they included the monitored period and more recent years (if it is possible in terms of data availability). The monograph is written in plain language.

The main aim of this publication - the approach to the issue of sovereign funds - has been fulfilled. The authors demonstrated their expertise and knowledge of the issue in theoretical and practical terms. I believe that the publication will certainly find a positive response both among students, professionals from the academic, public and business community and readers who want to develop their knowledge of global financial markets.

\author{
Ing. Liběna Černohorská, Ph.D. \\ University of Pardubice \\ Faculty of Economics and Administration \\ Institute of Economic Sciences \\ libena.cernohorska@upce.cz
}

DOI: 10.15240/tul/001/2015-3-015 